\title{
INTRA UTERINE CONDOM BALLOON TAMPONADE-A LIFE SAVING MEASURE IN ATONIC PPH
}

\author{
Alka Pandey and Chitra Sinha
}

\author{
DOI: http://dx.doi.org/10.24327/ijrsr.2017.0803.0107
}

\section{ARTICLE INFO}

\section{Article History:}

Received $17^{\text {th }}$ December, 2016

Received in revised form $21^{\text {st }}$

January, 2017

Accepted $05^{\text {th }}$ February, 2017

Published online $28^{\text {th }}$ March, 2017

\begin{abstract}
Objective-To assess the effectiveness of intrauterine condom balloon tamponade in achieving haemostasis, in cases of atonic post partum haemorrhage.

Design-Prospective observational study

Setting-Emergency labour room of Obstetrics and Gynaecology Department of a tertiary care hospital \& teaching institution

Study period- January 2013-December 2015

Material \& methods-Thirty women having atonic PPH in whom active management of third stage of labour and uterotonics were not effective, were selected for this study.

With full aseptic and antiseptic precautions a condom was tied on a nasogastric tube and was inserted into the uterine cavity, the distal end of the tube was connected to an IV set through which $250-500 \mathrm{cc}$ normal saline was instilled to inflate the condom so as to achieve haemostasis.

Observation- $46.6 \%$ women were between $25-30$ yrs of age, $53.3 \%$ were multigravida. The gestational age was between $37-40$ weeks in $80 \%$ cases. In $53.3 \%$ cases, there was some associated risk factor for PPH. In $72.72 \%$ cases placenta took alonger time to separate.

In $66.6 \%$ women $250-500 \mathrm{ml}$ saline was instilled to inflate the condom balloon. It took $10-15$ minutes time from insertion of the condom balloon catheter to achieve haemostsis in $73.3 \%$ women. The condom balloon catheter was kept in situ for 12-24 hrs in $73 \%$ women. Success rate of balloon tamponade was $90 \%$. There was no infection in any case.

Conclusion-Intrauterine condom balloon tamponade is effective, cheap and requires little skill. It can be used as a second line intervention in the management of atonic PPH. Skilled birth attendants in remote areas can use this technique and then transfer the woman to tertiary care unit. This will help in saving many maternal lives.
\end{abstract}

Copyright (C) Alka Pandey and Chitra Sinha, 2017, this is an open-access article distributed under the terms of the Creative Commons Attribution License, which permits unrestricted use, distribution and reproduction in any medium, provided the original work is properly cited.

\section{INTRODUCTION}

Post partum haemorrhage accounts for a quarter of maternal deaths ${ }^{1}$. Death from PPH can largely be avoided through proper prevention, diagnosis and management ${ }^{2,3}$. $80 \%$ of maternal deaths can be prevented through actions that are effective and affordable in developing country settings [WHO, UNICEF \& UNFPA -2001]. Active management of third stage of labour can prevent up to $60 \%$ cases of $\mathrm{PPH}^{4}$. But it still accounts for $31 \%$ of maternal deaths in Asia ${ }^{5}$.

Uterine atony is the commonest cause of PPH accounting for $70-80 \%$ of cases ${ }^{6,7}$. If bleeding is controlled immediately severe $\mathrm{PPH}$ can be prevented and we can save the patient from severe morbidity and mortality. Unfortunately many women in resource scarce settings do not have access to good quality care for the delivery. They are therefore at high risk of morbidity or death consequent to $\mathrm{PPH}^{8,9}$. Uterotonic agents are the first line of management. If they fail, intrauterine balloon tamponade has been used as a second line procedure in women with $\mathrm{PPH}^{10}$.

WHO has recommended the use of balloon tamponade for the treatment of PPH due to uterine atony in its updated guidelines [2012]. FIGO included uterine balloon tamponade as a recommended second line intervention for the treatment of $\mathrm{PPH}$ in their updated guidelines $2012^{11}$. In 1983 Goldrath published evidence that inserting foley's catheter in uterine cavity and inflating it with water could achieve tamponade ${ }^{12}$. Among the type of balloons used to produce tamponade are Sengstaken-Blackmore tube ${ }^{13,14}$ - the Rush catheter ${ }^{15}$, the Bakri tamponade balloon catheter ${ }^{16,17}$ and the male condom balloon catheter $^{18,19,20}$.

Dr. Sayeba Akhtar introduced a novel device the male condom tied to the rubber catheter and used it forintrauterine balloon 
tamponade in 2001. This is very cost effective and easy to use method which requires minimum skill.

This study was carried out to find out the efficacy of intrauterine condom balloon tamponade in controlling atonic PPH.

\section{MATERIAL AND METHODS}

30 cases of post partum haemorrhage due to uterine atony were selected for the study from emergency \& labour ward, Department of Obstetrics \& Gynaecology of a tertiary care hospital \& teaching institution. This prospective study was done between the period of January 2013 to December 2015.

Selection criteria-Cases of atonic PPH following vaginal delivery in which $1^{\text {st }}$ line of management by uterotonic drugs had failed.

For PPH WHO criteria has been used

- $\quad \geq 500 \mathrm{ml}$ of bleeding

- $\quad \geq 1000 \mathrm{ml}$ of bleeding in cases of severe PPH

\section{Exclusion Criteria}

- Traumatic PPH

- Known cases of bleeding disorders

- Secondary PPH

- $\quad \mathrm{PPH}$ in cases of Caesarean section

- Infection

\section{Clinical evaluation of the all the cases was done in following} manner

- History

- General examination

- Systemic examination

- Per abdomen examination

- Pelvic examination

\section{Laboratory investigation}

- Complete blood count

- BTCT

- $\quad$ Rh typing \& $\mathrm{ABO}$ grouping

- Routine examination of urine

- $\mathrm{HIV}$, Australia Antigen and HCV

- Coagulation profile if needed

\section{Resuscitation of the patient was done by}

- Establishment of I V line bytwo large bore intracath no 14

- Crystalloid infusion (normal saline/ringers lactate)

- Colloids if needed

- Oxygen by mask (6-8 lit/min).

- Syntocinon drip- 20 units in $500 \mathrm{ml}$ of normal saline

- Antibiotics - Broad spectrum antibiotics- Ceftriaxone 1gm IV-BD, Amikacin 500mg BD and Metronidazole IV.

- Blood sample for cross matching

- Blood \& blood products according to the severity of PPH \& need.

- $\quad$ Transfer of the patient to Operation Theater

\section{METHODS}

Male latex condom which is available in hospital was used in the study.

The patient was put in lithotomy position and with full aseptic and antiseptic precautions this procedure was done. Indwelling catheterization was done. Condom was tied on the nasogastric tube with a thread $4-5 \mathrm{~cm}$ from the tip. With the help of two Sims speculum the cervix was visualized. Anterior lip of the cervix was held by the sponge holder. The condom which was tied on the nasogastric tube was inserted inside the uterine cavity with the help of sponge holder or digitally for up to 14$15 \mathrm{~cm}$. IV transfusion set was attached to the distal end of the tube and the condom was slowly filled with normal saline. After filling the condom with $250 \mathrm{ml}$ of fluid we watched for the bleeding [tamponade test]. If there was no bleeding or the bleeding reduced we waited and observed. If the bleeding continued the condom was inflated with more fluid. The minimum amount of fluid which we used for this study was $250 \mathrm{ml}$ and maximum $500 \mathrm{ml}$. We waited for 5-15 minutes to see the response, if the bleeding was controlled we clipped the nasogastric tube at $6-7 \mathrm{~cm}$ from the cervix and cut the remaining portion of the distal end. Stopper was applied on the distal end of the vaginal portion.

A tight vaginal pack was done to keep the condom catheter in position. Oxytocin drip was given for 6 hours and prophylactic antibiotics were given. When the woman became stable and vital parameters improved we kept this condom balloon in situ for a minimum of 12-24 hrs. Then we slowly deflated the condom over 10-15 minutes and if there was no bleeding we removed it from the uterus and vagina. Close monitoring of the woman's vital was done for $24 \mathrm{hrs}$. In three patients, in which bleeding was not controlled by this method, surgical intervention had to be done.

\section{Observations}

Table I Distribution of cases according to age

\begin{tabular}{ccc}
\hline Age (yrs) & No. of cases & Percentage \\
\hline $20-24$ Yrs & 6 & 19.99 \\
$25-30$ & 14 & 46.66 \\
$>30$ & 10 & 33.35 \\
Total & 30 & 100 \\
\hline
\end{tabular}

Majority of cases belonged to age group of 25-30 Yrs Mean Age $=13.62 \pm 1.231$ Yrs

$\mathrm{P}$-value $=0.505$ (Not Significant)

Table II Distribution of cases according to Parity

\begin{tabular}{ccc}
\hline Parity & No. of cases & Percentage \\
\hline Primi para & 9 & 30 \\
$2-4$ & 16 & 53.33 \\
Grand multipara & 5 & 16.66 \\
Total & 30 & 100 \\
\hline
\end{tabular}

Most of the cases were multipara

P. Value 0.001

Table III Distribution of cases according to the period of gestation

\begin{tabular}{ccc}
\hline Gestational & No. of cases & Percentage \\
\hline Term $37-40$ wks & 24 & 80 \\
$>40$ wks & 06 & 20 \\
Total & 30 & 100 \\
\hline
\end{tabular}

Maximum no. of cases had 37 to 40 wks gestation. P. Value $=0.472$ (Not Significant) 
Table IV Distribution of cases according to Risk factors

\begin{tabular}{ccc}
\hline Risk Factors & No. of cases & Percentage \\
\hline Present & 16 & 53.33 \\
Absent & 14 & 46.66 \\
Total & 30 & 100 \\
\hline
\end{tabular}

$53.33 \%$ cases had associated risk factors.

P. Value -0.001

Table $\mathbf{V}$ Type of associated risk factor present in present in 16 cases

\begin{tabular}{ccc}
\hline Risk factors & No. of cases & Percentage \\
\hline PET & 4 & 25 \\
Eclampsia & 2 & 12.5 \\
Prolonged Labour & 3 & 18.75 \\
Previous H/O PPH & 3 & 18.75 \\
Severe anaemia & 2 & 12.5 \\
Severe anaemia with PET & 1 & 6.25 \\
Twin pregnancy & 1 & 6.25 \\
Total & 16 & 100 \\
\hline
\end{tabular}

Highest probability of PPH is seen in cases of preeclampsia. P. Value $-<0.05$

Table VI Distribution cases according to active management of $3^{\text {rd }}$ stage of labour (AMTSL)

\begin{tabular}{ccc}
\hline AMTSL & No. of cases & Percentage \\
\hline $\begin{array}{c}\text { AMTSL done } \\
\text { (Referred from outside )Either not } \\
\text { done or no record but received } \\
\text { uterotonic drugs after PPH }\end{array}$ & 22 & 73.33 \\
$\quad$ Total & 8 & 26.66 \\
\hline
\end{tabular}

In $73.33 \%$ cases AMTSL is done.

P. Value- 0.001

Table VII Duration of $3^{\text {rd }}$ stage of labor in 22 cases in which AMTSL was done

\begin{tabular}{ccc}
\hline Duration & No. of cases & Percentage \\
\hline$>5-15$ minutes & 6 & 27.27 \\
$>15-20$ minutes & 12 & 54.54 \\
$>20$ minutes & 4 & 18.18 \\
Total & 22 & 100 \\
\hline
\end{tabular}

$3^{\text {rd }}$ stage was prolonged in $72.72 \%$ cases.

P. Value $-<0.05$

Table VIII Amount of Blood loss observed in the study group

\begin{tabular}{ccc}
\hline Amount of blood loss & No. of cases & Percentage \\
\hline $500-750$ & 21 & 70 \\
$>750-1000$ & 9 & 30 \\
Total & $\mathbf{3 0}$ & $\mathbf{1 0 0}$ \\
\hline
\end{tabular}

Table IX Amount of fluid used to inflate the balloon (Condom)

\begin{tabular}{ccc}
\hline Amount of fluid & No. of cases & Percentage \\
\hline $250-350 \mathrm{ml}$ & 10 & 33.33 \\
$350-500 \mathrm{ml}$ & 20 & 66.66 \\
Total & 30 & 100 \\
\hline
\end{tabular}

P. Value -0.452

Table X Duration of time in achieving hemostasis

\begin{tabular}{ccc}
\hline Duration of time & No. of cases & Percentage \\
\hline $5-8$ minutes & 18 & 60 \\
$9-15$ minutes & 12 & 40 \\
& 30 & 100 \\
\hline
\end{tabular}

The duration of time in achieving hemostasis was from 5 to 8 minutes in $60 \%$ cases \& 9 to 15 minutes in $40 \%$

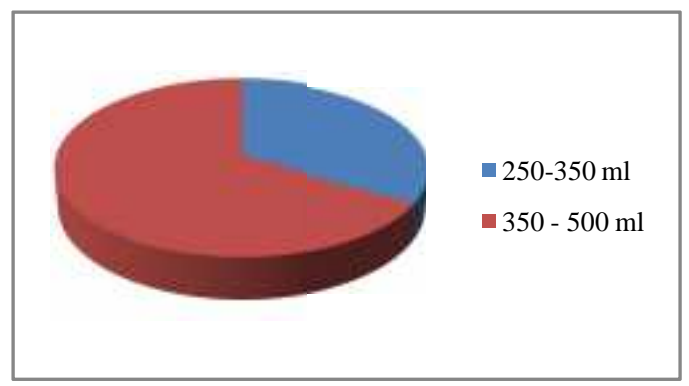

Graph Amount of fluid used to inflate the balloon (condom)

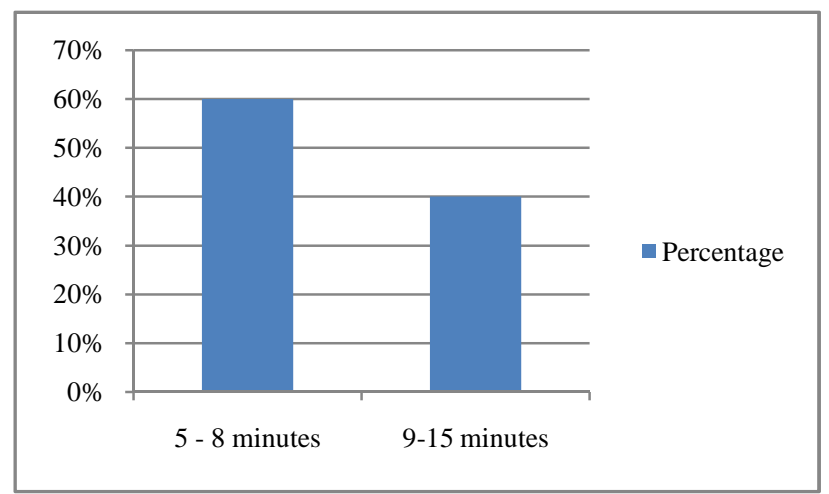

Graph Duration of time in achieving hemostasis

Table XI Duration of condom catheter kept inside the uterus

\begin{tabular}{ccc}
\hline Duration & No. of cases & Percentage \\
\hline $12 \mathrm{hrs}$ & 8 & 26.66 \\
$\geq 12-24 \mathrm{hrs}$ & 22 & 73.33 \\
Total & 30 & 100 \\
\hline
\end{tabular}

Condom balloon was kept in situ for more than 12 hours in $73.33 \%$ cases. P. Value $=0.002$

Table XII Success rate of balloon tamponade

\begin{tabular}{ccc}
\hline Outcome & Cases & Percentage \\
\hline Successful & 27 & 90 \\
$\begin{array}{c}\text { Surgical intervention } \\
\text { needed }\end{array}$ & 3 & 10 \\
Total & 30 & 100 \\
\hline
\end{tabular}

In $90 \%$ cases balloon tamponade was successful P. value -0.001

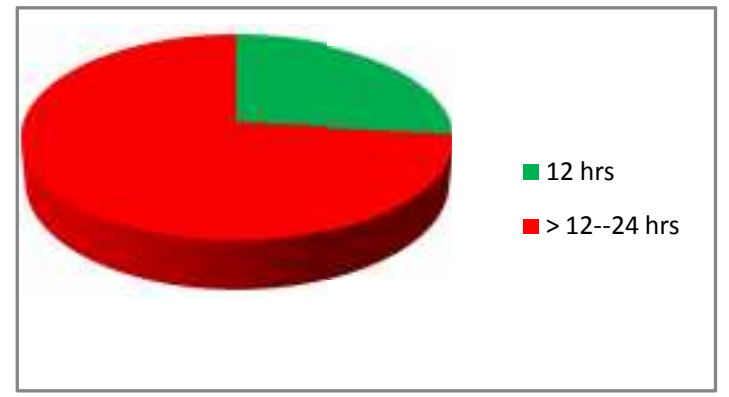

Graph Duration of condom catheter kept inside the uterus

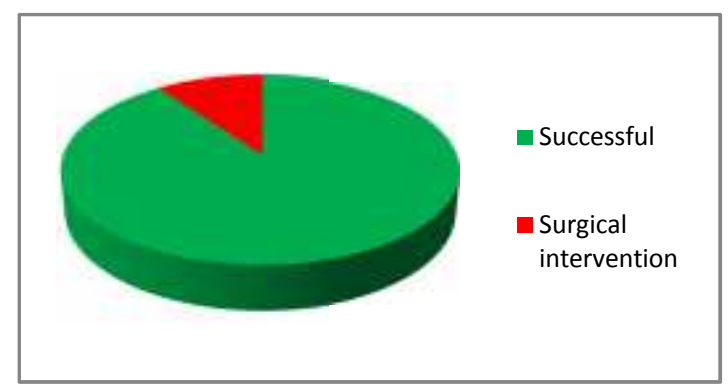

Graph Success rate of balloon tamponade 
Table XIII Types of surgical intervention

\begin{tabular}{cc}
\hline Types of surgical intervention & No. of cases \\
\hline Peripartum hysterectomy & 1 \\
B-Lynch suture & 1 \\
Haultains operation & 1 \\
\hline $10 \%$ cases required surgical intervention &
\end{tabular}

$10 \%$ cases required surgical intervention

P. Value $=<0.05$

In 1 case balloon tamponade was done for PPH with inversion of uterus. On removing condom catheter PPH remained controlled but inversion recurred (of lesser degree) which required surgical correction.
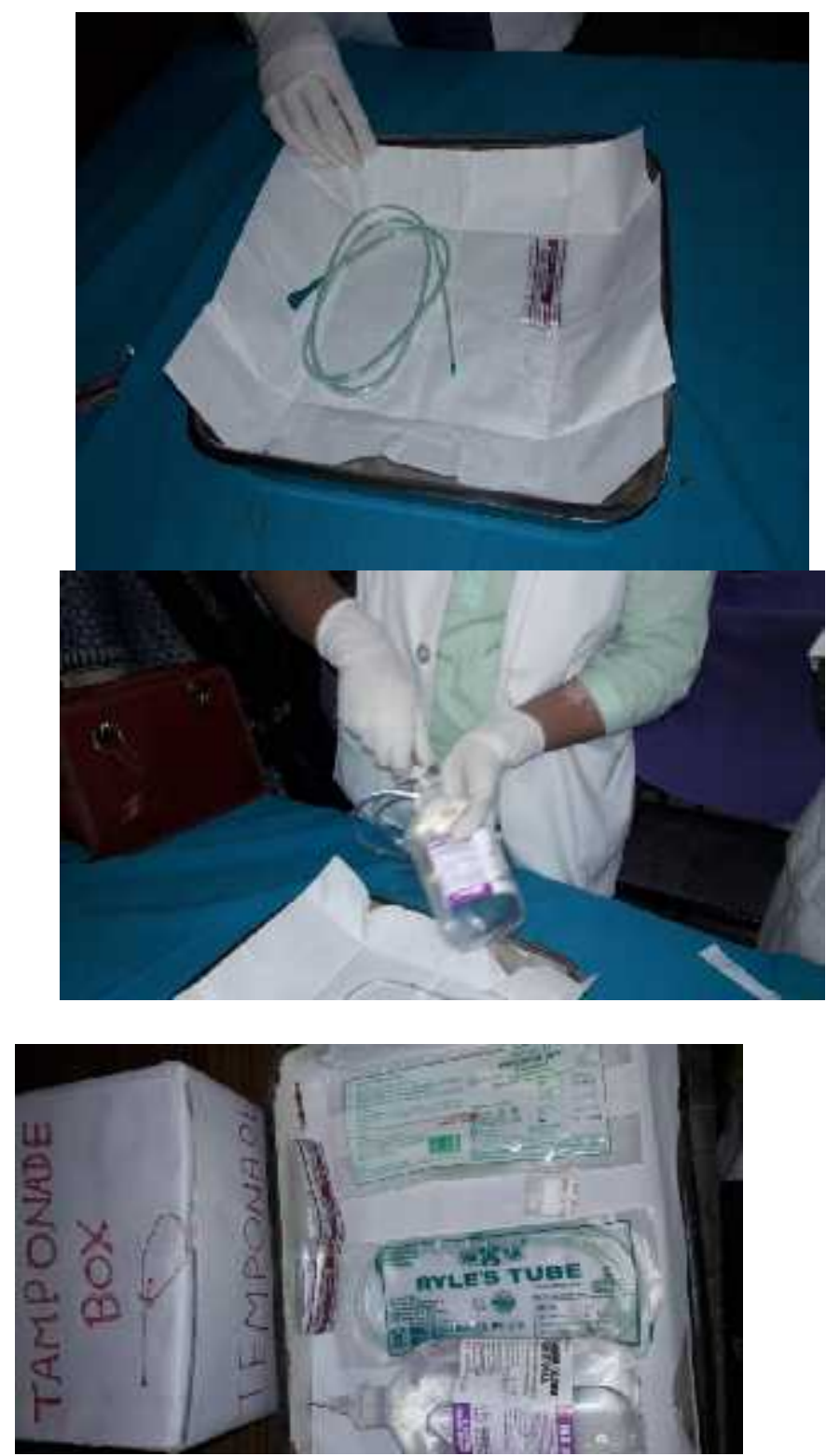

\section{DISCUSSION}

Thirty cases of atonic PPH were selected for this study to know the effect of intrauterine condom balloon tamponade in controlling atonic PPH in which the $1^{\text {st }}$ line management of utertonic drugs had failed.

K. Tindell et $a l^{21}$ did a systematic review of trials of intrauterine balloon tamponade for the treatment of postpartum haemorrhage in resource poor settings (2012). The studies used various types of UBT (Uterine Balloon Tamponade) including condom catheters, $(n=193)$, Foleys catheter, $(n=5)$ and Sengastaken-Blakemore, Oesophageal tube, $(n=1)$. UBT successfully treated PPH in 234 out of 241 women. We have used condom balloon catheter.

The presumed mechanism of action of the tamponade in stopping the bleeding is by creating an intrauterine pressure which exerts hydrostatic pressure on the capillaries and veins in the uterus. The pressure does not necessarily have to be higher than the systemic arterial pressure.
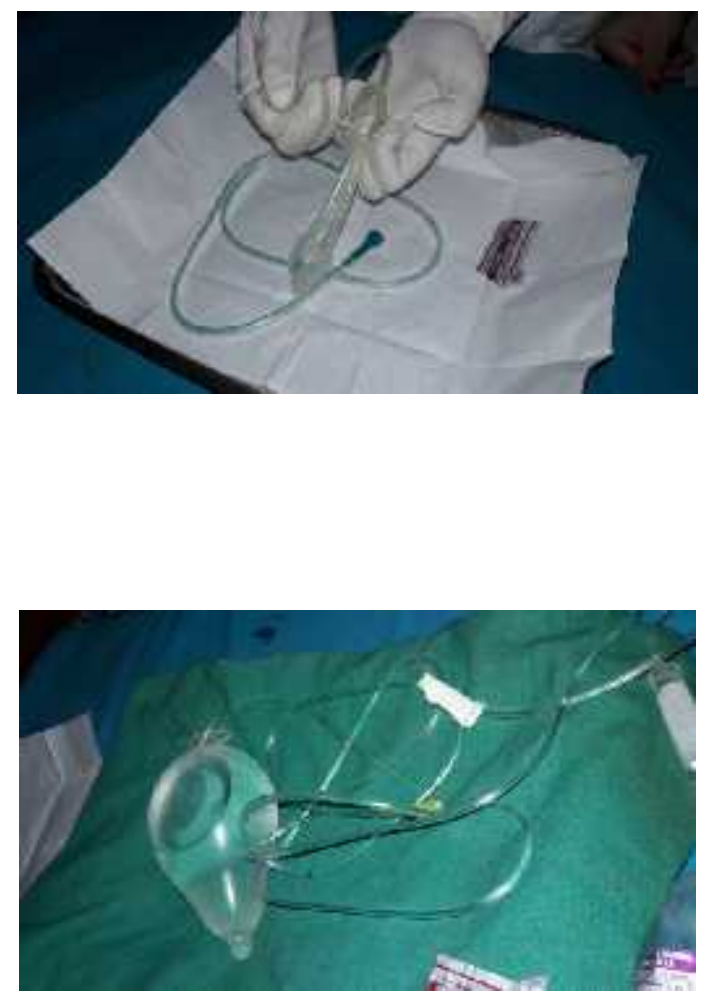

In addition, hydrostatic pressure effect of the balloon on the uterine arteries has been proposed and stimulation of uterine contractions by balloon in the cervix has also been demonstrated.

Majority of our patient $46.6 \%$ were in the age group of 25-30 years and $53.3 \%$ cases were multipara. In Tindell review ${ }^{21}$ women who underwent UBT for PPH ranged in parity from 1 to 10 and were aged $18-40$ years.

The gestational age was 37 to 40 weeks in our series. Active management of labour was done in $73.3 \%$ of our cases. In Tindells review ${ }^{21}$ there were 9 studies in which active management of labour was done. There were associated risk factors in $53.3 \%$ cases in our study. Studies of Doumouchtsis SK et $a l^{22}$, Claudio G. Sosa ${ }^{23}$, Xione Q. et $a l^{24}$, A Briley et $a l^{25}$ and Akhtar S. had similar observations.

The estimated blood loss in our study was from 500-1000 ml. The highest reported estimated blood loss successfully managed by UBT was $5000 \mathrm{ml}$ in Thapas study reviewed by Tindell. In our series we had selected all cases of atonic PPH 
where as in the review by Tindell ${ }^{21}$ additional causes of PPH included coagulopathy, placenta accreta and placenta previa.

The third stage of labour was prolonged $>15-20 \%$ in 12 cases $(72.72 \%)$. In those cases in which the third stage of labour was prolonged there was atonic $\mathrm{PPH}$.

We inserted the condom catheter in the uterine cavity manually and in some cases by sponge holding forceps. We used gravity inflation and an intravenous infusion set to inflate the condom. Once inside the uterus we used $250-500 \mathrm{ml}$ of saline to inflate the condom and inflation was stopped when bleeding ceased or there was resistance to saline.

The time required for PPH to be controlled after placement of condom catheter ranged from 5-15 minutes in our study. This had similarity with other studies reviewed by Tindell ${ }^{21}$. We packed the vagina with gauze dressings to prevent catheter from falling out of the uterus once bleeding had ceased. Seven of the eight studies $(n=191)$ reviewed by Tindell ${ }^{21}$ used a vaginal pack to prevent condom catheter from falling out of the uterus.

We had given oxytocin drip for six hours from the time of insertion of the condom catheter. Tindell ${ }^{21}$ in his review has observed that in six studies $(n=118$ women) an oxytocin drip was given upto 6 hours from the time of insertion of catheter. Shivkar et $a l^{26}$ did not report the use of any uterotonics concurrent with condom catheter $(n=73)$. In one successful case reported by Rathore, Manaktala et $a l^{27}$ oxytocin was administered only during the removal of condom catheter.

The catheter was kept in situ for 12-24 hours in our study. In Tindell review ${ }^{21}$ the length of time reported between insertion of condom catheter and removal ranged from 6 hours to 72 hours. We deflated the catheter slowly from 10-30 minutes. The time taken to deflate the UBT varied from 10 minutes to 6 hours in Tindells review ${ }^{21}$.

We did not have infection in any case. In eight studies reviewed by Tindell $^{21}(n=193)$ in women using the condom catheter there were no reports of increased infection rate. Seven of the studies $(n=120)$ reported prophylactic use of broad spectrum antibiotics. Shivkar et $a l^{26}$ did not report using any antibiotic and reported no case of infection or fever in their series $(n=73)$. We used prophylactic antibiotic Ceftriaxone 1 gm IV twice, Amikacin 500mg IM twice daily and Metronidazole I.V infusion.

We had three failures for which surgical intervention was done. Rathore et $a l^{27}$ reported success in 25 of 26 women with one failure for which emergency hysterectomy was done. Shivkar et al reported 5 failures in their study for which surgical intervention was done.

In our study UBT was successful in $90 \%$ of cases in the review by Tindell ${ }^{21}$ the success rate of UBT varied from $93 \%$ to $100 \%$ in various studies.

\section{CONCLUSION}

Intrauterine condom balloon tamponade has been found to be effective in managing atonic post partum haemorrhage. It is easy, safe and effective and preserves fertility. It should be an integral part of labour ward protocols for management of post partum hemorrhage. It can be used by the skilled birth attendants for transferring the patient from remote periphery to tertiary care centres.

Hence, we conclude that intrauterine condom balloon tamponade is an effective method in saving maternal lives from PPH.

\section{References}

1. World Health Organization. Attending to 136 million births, every year: make every mother and child count: the world record 2005. 2005:62-63.

2. Karoshi M, Keith L, Challenges in managing postpartum haemorrhage in resource poor countries. Clin Obstet Gynecol 2009; 52:285-98.

3. Royal College of Obstetricians and Gynaecologists. Prevention and Management of Postpartum Haemorrhage. $1^{\text {st }}$ edn. London, RCOG 2009.

4. World Health Organization (WHO). MPS Technical Update: Prevention of Postpartum Haemorrhage by Active Management of the Third Stage of Labour. Geneva: WHO; 2006.

5. Impact International. Measuring and Addressing Outcomes after Pregnancy: A Holistic Approach to Maternal Health. Aberdeen, UK: Immpact International; 2007.

6. American College of Obstetricians and Gynaecologists. ACOG practice bulletin; clinical management guidelines for obstetrician gynecologists no. 76, October 2006: postpartum haemorrhage. Obstet Gynecol. 2006; 108: 1039-1047.

7. Bateman BT, Berman MF, Riley L.E, et al. The epidemiology of postpartum hemorrhage in a large, nationwide sample of deliveries. Anesth Analg. 2010; 110: 1368-1373.

8. Royal College of Obstetricians and Gynaecologists. Prevention and Management of Postpartum Haemorrhage. $1^{\text {st }}$ edn. London, RCOG 2009.

9. Walraven G. Wanyonyi S. Stones, W. Management of post-partum haeomorrhage in low income countries. Best pract Res Clin Obstet Gynaecol 2008; 22:1013-23.

10. Miller S. Martin HB, Morris JL Antishock garment in postpartum haemorrhage. Best Pract Res Clin Obstet Gynaecol 2008; 22:1057-74.

11. FIGO. FIGO Guidelines: Prevention and Treatment of Postpartum Hemorrhage in Low-Resource Settings. International Journal of Gynaecology and Obstetrics. 2012; 117:108-118.

12. Goldrath MH. Uterine tamponade for the control of acute uterine bleeding. American Journal of Obstetrics and Gynecology. 1983;147(8):869-872

13. Condous GS, Arulkumaran S, Symonds I, Chapman R, Sinha A, Razvi K, The "tamponade test" in the management of massive postpartum haemorrhage obstet Gynecol 2003; 101 (4) 767-72.

14. Macrocci I, Scenario B, Postpartum haemorrhage and intrauterine balloon tamponade: a report of 3 cases $J$ Reprod Med 1999; 44:112-6.

15. Johanson R, Kumar AL, Obrai M, Young P, Management of massive PPH : use of Hydrostatic balloon catheter to avoid laparotomy. BJOG 2001; 108:420-2

16. Gronvall M, Tikkanen M, Tallberg E, Paavonen, Stefanovic V, Use of Bakri Balloon tamponade in the 
treatment of postpartum haeomorrhage: a series of 50 cases from a tertiary teaching hospital, Act Obstet Gynaecol Scand 2013; 92:433-8.

17. Bakri Y. Amri A, Abdul Jabbar F, Tamponade balloon for obstetrical bleeding. Int J Gynaecol Obstet 2001; $74: 139-42$.

18. Airede LR, Nnadi CD, The use of the condom catheter for the treatment of postpartum haemorrhage-the Sokoto experience. Trop Doct 2008; 38:84-6.

19. Bagga R, Jain V, Sharma S, Suri V. Postpartum haemorrhage in two women with impaired coagulation successfully managed with condom catheter tamponade, Indian J Med Sci 2007; 61:157-8.

20. Akhter S, Begum MR, Kabir J, Condom hydrostatic tamponade for massive postpartum haemorrhage. Int $J$. Gynaecol Obstet 2005; 90:134-5.

21. K Tindell, R Garfinkel et al. Uterine Balloon tamponade for the treatment of postpartum haemorrhage in resource poor setting: a systematic review, 2012 www.bjog.org.

22. Doumouchtsis SK, Papageorghiou AT, Arulkumaran S. Systematic review of conservative management of postpartum hemorrhage: what to do when medical treatment fails. Obstetrical and Gynecological Survey. 2007; 62(8): 540-547.

$* * * * * * *$
23. Claudio G. Sosa. Fernando Althabe. et al. Factor associated with post partum hemorrhage with vaginal birth. obstetric \& gynaecol, 2009 June J 113 (6): 13B-1319.

24. Xione Q GY chen H M. Risk factors for PPH in rural women: 1994, 29: 582-5 635 [Pub Med]

25. Briley, PT Seed, GTydeman et al, Reporting error, incidence and risk factors for postpartum haemorrhage prospective observational study, BJOJ 2014 Jun: 121970:768-888.

26. Shivkar Krishna S, Khadilkar Suwarna S, Gandhewar Manisha. Pressure Balloon Therapy in Uncontrolled Obstetrical Haemorrhage. The Journal of Obst and Gynaecology of India, Volume 53, No. 4 July- Aug 2003.

27. Rathore AM, Gupta S, Manaktala U, Gupta S, Dubey C, Khan M. Uterine tamponade using condom catheter balloon in the management of non-traumatic postpartum haemorrhage. J. Obstet Gynaecol Res. 2012; 38:1162-7.

How to cite this article:

Alka Pandey and Chitra Sinha.2017, Intra Uterine Condom Balloon Tamponade-A Life Saving Measure in Atonic Pph. Int J Recent Sci Res. 8(3), pp. 16234-16239. DOI: http://dx.doi.org/10.24327/ijrsr.2017.0803.0107 